Acta Horticulturae et Regiotecturae 2

Nitra, Slovaca Universitas Agriculturae Nitriae, 2019, pp. 75-79

\title{
IMPACT ASSESSMENT OF VEGETATION GROWTH ON SOIL EROSION OF A LANDFILL COVER SURFACE
}

\author{
Janarul SHAIKH ${ }^{1 *}$, Sudheer Kumar YAMSANI ${ }^{2}$, Manash Jyoti BORA ${ }^{3}$, Sreedeep SEKHARAN ${ }^{3}$, Ravi \\ Ranjan RAKESH ${ }^{4}$, Atharva MUNGALE ${ }^{5}$, Sanandam BORDOLOI ${ }^{3}$ \\ ${ }^{1}$ C. V. Raman College of Engineering, Bidyanagar, Mahura, Janla, Bhubaneswar, Odisha, India \\ ${ }^{2}$ Vaagdevi College of Engineering, Warangal, Telangana, India \\ ${ }^{3}$ Indian Institute of Technology Guwahati, Kamrup, Assam, India \\ ${ }^{4}$ Bhabha Atomic Research Centre, Mumbai, Maharashtra, India \\ ${ }^{5}$ Veermata Jijabai Technological Institute, Mumbai, Maharashtra, India
}

\begin{abstract}
Soil erosion is a very common phenomenon encountered at many sloped earthen geotechnical structures. For instance, the surface soil of an inclined landfill cover system undergoes the erosion due to various adverse atmospheric variants. This is one of the major causes for performance failure in the cover system. However, previous researchers have rarely conducted the study for field assessment of soil erosion in high rainfall tropical regions such as northeast India. The literature advocates the utilization of vegetation for erosion management. This study investigated the impact of vegetation growth on soil erosion of a cover surface layer under both natural and controlled artificial rainfall. The soil erosion was monitored by collecting the soil loss due to rainfall. Vegetation growth was evaluated based on photographic image analyses. The study clearly indicates that the vegetation growth can contribute to reduction of soil erosion from the landfill cover surface.
\end{abstract}

Keywords: vegetation growth, water infiltration, soil erosion, landfill cover, artificial rainfall

Growing demand for energy and improved infrastructure have led to increase in high contaminant wastes that need sustainable isolation systems for their safe containment in an engineered landfill (Kumar et al., 2008; EEA, 2013). Multilayered composite cover system is usually constructed over a landfill after its full capacity to secure the global ecosystem from the underlying wastes (Morris and Barlaz, 2011; Yamsani, Sreedeep and Rakesh, 2016). The landfill cover structure experiences various types of adverse phenomena due to different weather variants. Rainfall induced soil erosion of cover surface layer is one such phenomenon which causes deterioration in performance efficiency of landfill cover systems (Vereecken, Kollet and Simmer, 2010). Failure investigations of several existing waste containment facilities have identified the erosion to be the main cause for degradation of structural stability and performance (Huvajsarihan and Stark, 2008). Erosion of surface soils is affected by multiple factors namely soil water content, soil density, vegetation growth, anticipated rainfall, wind direction, soil type, slope length and gradient, etc. (Prosdocimi, Cerda and Tarolli, 2016; Nearing et al., 2017; Sachs and Sarah, 2017). There are different erosion management practices such as the use of geotextile (Luo et al., 2013), berm construction, mulching (Wang et al., 2015), vegetation growth (Butt, Waoas and Mahmood, 2010). The literature strongly recommends the use of vegetation for controlling soil erosion from sloped earthen structures such as landfill cover systems. However, the field investigation of soil erosion from surface layer of any landfill cover system constructed in a high rainfall tropical region such as northeast India has not been carried out previously.

The aim of the study is to evaluate the impact of vegetation growth on soil erosion of a landfill cover surface under the natural and controlled artificial rainfall. The soil erosion has been measured weekly by determining the mass of soil loss due to precipitation. The study utilized the photographic image analyses of vegetated surface to identify the role of vegetation growth to affect the soil erosion from the landfill cover surface. The hypothesis of the present study is to explore the survival period of the landfill cover system due to the positive effect of vegetation growth on the surface layer to prevent its soil erosion.

\section{Material and methods}

\section{Construction of experimental cover setup}

A pilot experimental field cover system was constructed at $5 \%$ slope near geotechnical laboratory at the Indian Institute of Technology Guwahati, India $\left(26.18^{\circ} \mathrm{N}, 91.40^{\circ} \mathrm{E}\right)$. The experimental cover setup consisted of a fixed masonry construction to accommodate pilot cover system, a rainfall simulation system and a collection chamber of accumulated soil loss. The schematic outline and the pictorial view of the 
experimental setup are shown in Fig. 1. The construction of experimental set-up was done according to standard practices. The leakage through the lateral walls or base was restricted by using impermeable masonry finishing. Medium plastic red soil (RS) was used to construct top surface layer of the field cover setup. RS was collected locally from the hilly area of Guwahati city. It is a medium plastic silty soil and qualifies for the requirement of surface soil layer in the cover system (USEPA, 1989; Landreth et al., 1991). The basic physical, geotechnical and chemical properties of the soil materials were investigated using standard laboratory procedures reported in the relevant code of Indian standard (IS) or international American society of testing and materials (ASTM) and presented in Table 1.

\section{Rainfall simulator}

The rainfall simulator was made of four "Full Cone square spray $1 / 2 \mathrm{HH}-40 W S \mathrm{~W}$ " nozzles from Spraying Systems Co. fitted to a $12 \mathrm{~mm}$ diameter pipe at a height of $2 \mathrm{~m}$ from ground surface. An interferential, single jet, super dry straight reading type, hermetically sealed water meter confirming to ISO-4064, controlled the inlet pressure for rain simulator. The rainfall simulator was calibrated for intensity versus inlet pressure before starting the experimentation of the field setup. The spatial uniformity was established in terms of the coefficient of uniformity (CuC) presented in the equation 1 (Christiansen, 1941). Table 2 summarized the rainfall calibration results, which indicate that the simulated rainfall intensity and raindrop size increased with increase in the inlet pressure. The uniformity was satisfactorily recorded in between 80 to $90 \%$. The raindrop size was evaluated using the flour pellet method defined by Kincaid et al. (1996).

$$
\mathrm{CuC}=\left(1-\frac{\sum_{1}^{N}\left|X_{i}-\bar{X}\right|}{N \bar{X}}\right) 100
$$

where:

CuC - the coefficient of uniformity (\%) $X_{i}-$ is the rainfall at any measurement location $(\mathrm{mm})$

$X \quad$ - the mean rainfall amount $(\mathrm{mm})$

$N$ - the number of locations chosen for measuring rainfall

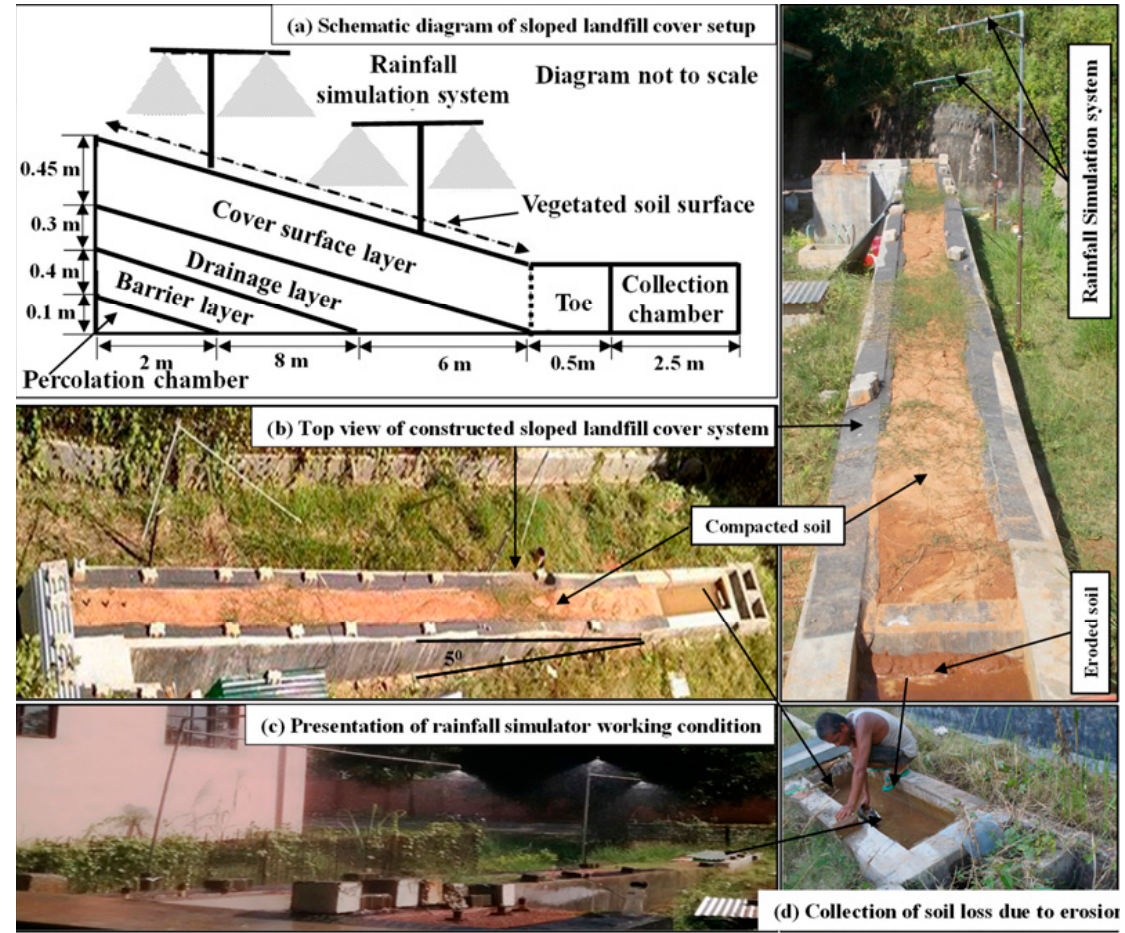

Figure 1 Schematic diagram of test cover setup and pictorial view after its construction

Table 1 Basic characteristics of soil material used in the study

\begin{tabular}{|c|c|}
\hline Properties & Red soil (RS) \\
\hline \multicolumn{2}{|c|}{ General } \\
\hline Specific gravity, G & 2.65 \\
\hline Hygroscopic water content (\%) & 5 \\
\hline Saturated hydraulic conductivity $\left(\mathrm{m} \cdot \mathrm{s}^{-1}\right)$ & $2.9 \mathrm{E}-8$ \\
\hline Specific surface area $\left(\mathrm{m}^{2} \cdot \mathrm{g}^{-1}\right)$ & 55 \\
\hline Linear shrinkage (\%) & 2 \\
\hline Free swell index (\%) & 10 \\
\hline \multicolumn{2}{|c|}{ Particle size distribution } \\
\hline$\%$ of gravel (>4.75 mm) & 0 \\
\hline$\%$ of coarse sand $(2.00-4.75 \mathrm{~mm})$ & 17 \\
\hline$\%$ of medium sand $(0.425-2.00 \mathrm{~mm})$ & 16 \\
\hline$\%$ of fine sand $(0.075-0.425 \mathrm{~mm})$ & 16 \\
\hline$\%$ of silt $(0.002-0.075 \mathrm{~mm})$ & 19 \\
\hline$\%$ of clay $(<0.002 \mathrm{~mm})$ & 32 \\
\hline \multicolumn{2}{|l|}{ Atterberg's limits } \\
\hline Liquid limit (\%) & 42 \\
\hline Plastic limit (\%) & 22 \\
\hline Shrinkage limit (\%) & 21 \\
\hline Plasticity index (\%) & 20 \\
\hline USCS classification & ML \\
\hline \multicolumn{2}{|c|}{ Standard compaction } \\
\hline Optimum moisture content, OMC (\%) & 20 \\
\hline Maximum dry density, MDD (g.cm $\left.{ }^{-3}\right)$ & 1.73 \\
\hline
\end{tabular}


Table 2 Characteristics of simulated rainfall events

\begin{tabular}{|c|c|c|c|c|c|c|}
\hline Nozzle type & $\begin{array}{c}\text { Orifice } \\
\text { diameter (mm) }\end{array}$ & $\begin{array}{l}\text { Pressure } \\
(\mathrm{kPa})\end{array}$ & $\begin{array}{l}\text { Flow meter } \\
\left(1 . \mathrm{min}^{-1}\right)\end{array}$ & $\begin{array}{c}\text { Rain drop size } \\
\text { (mm) }\end{array}$ & $\begin{array}{l}\text { Rainfall intensity } \\
\left(\mathrm{mm} \cdot \mathrm{hr} \mathbf{r}^{-1}\right)\end{array}$ & $\begin{array}{c}\text { Coefficient of } \\
\text { uniformity }(\mathrm{CuC})(\%)\end{array}$ \\
\hline \multirow{3}{*}{$\begin{array}{l}\text { Full Cone } \\
\text { square spray - } \\
1 / 2 \mathrm{HH}-40 \text { WSQ }\end{array}$} & \multirow{3}{*}{$\begin{array}{c}6.4 \mathrm{~mm} \\
\text { (maximum free } \\
\text { passage } 3.2 \mathrm{~mm} \text { ) }\end{array}$} & 70 & 15.2 & $2.1 \pm 0.1$ & $60 \pm 5$ & 87.3 \\
\hline & & 90 & 17.8 & $2.4 \pm 0.1$ & $80 \pm 5$ & 81.4 \\
\hline & & 120 & 19.7 & $2.9 \pm 0.2$ & $100 \pm 5$ & 89.7 \\
\hline
\end{tabular}

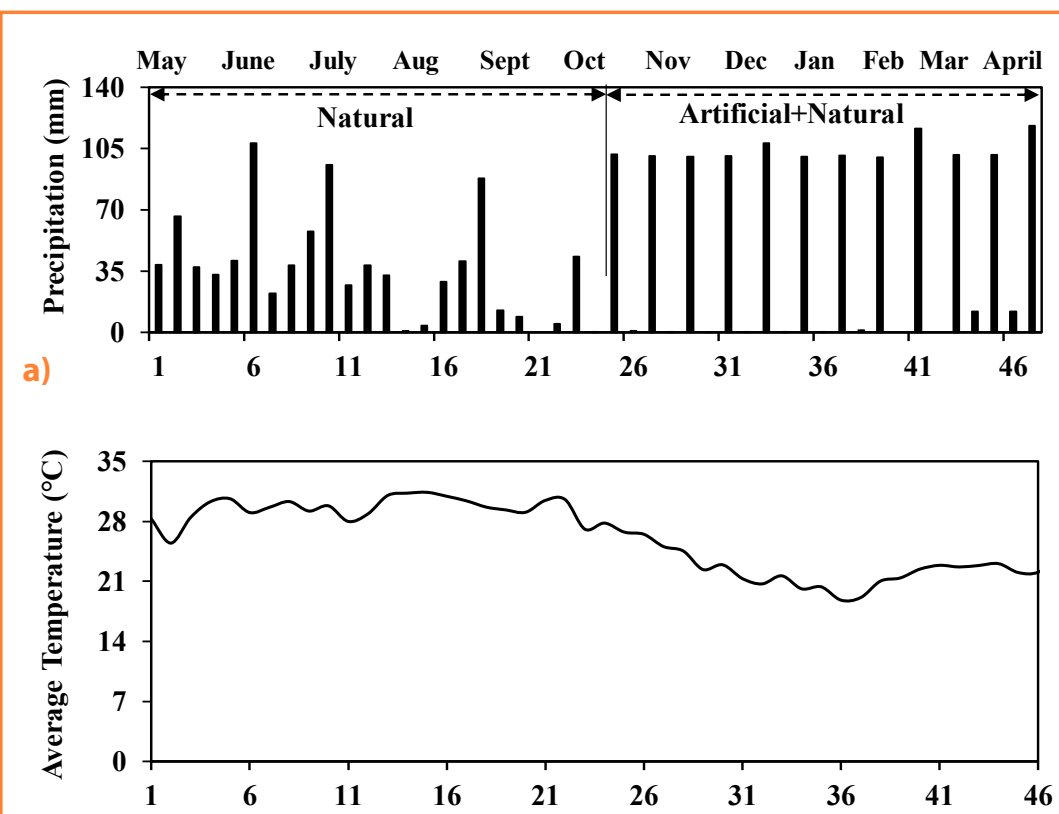

b)

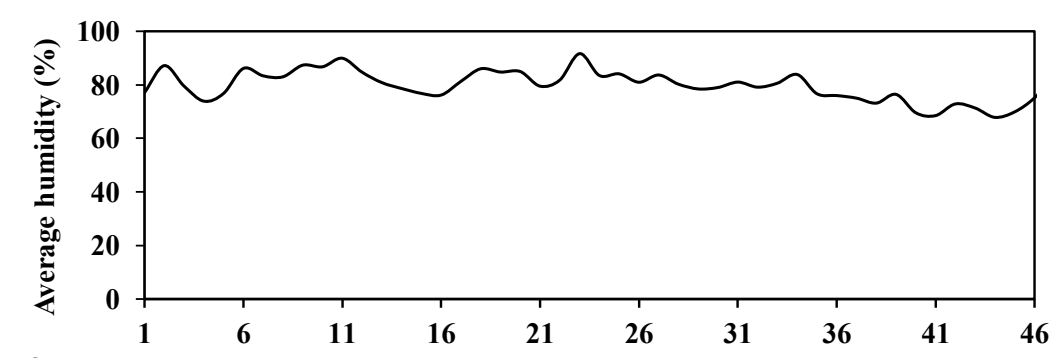

c)

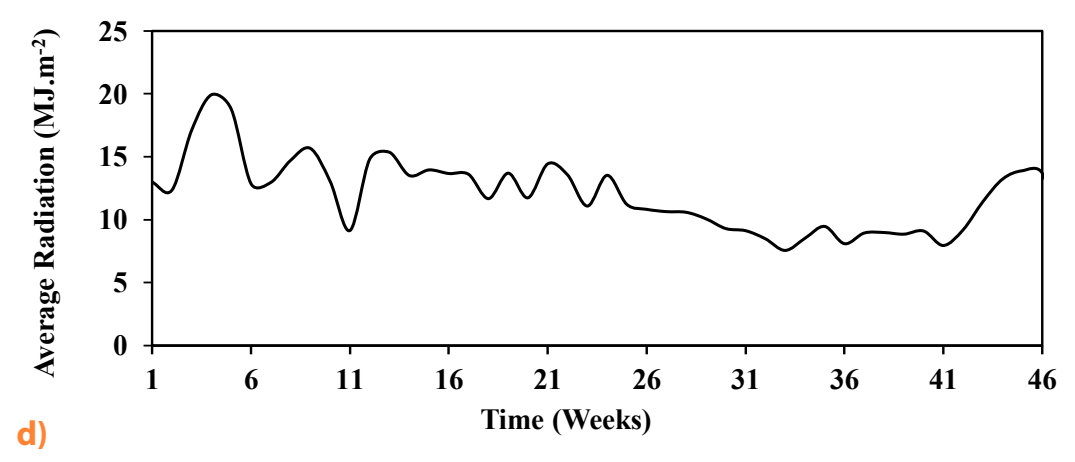

Figure 2 Various weather parameters during the monitoring period of the field cover setup

\section{Testing program and methods}

The sloped soil surface was initially exposed to natural weather variations for a period of six months (May -
October, 2016) during the monsoon period. The climatic variations in northeast India are of mixed type that includes heavy rainfalls and high temperatures, causing cyclic wetting and drying. The natural weather variations during the study period were monitored using microclimate weather station (Decagon devices Inc., 2015) installed near the experimental site. Fig. 2 presents various weather parameters. For systematic investigation, after completion of monsoon, rainfall events of about $100 \pm 5 \mathrm{~mm} \cdot \mathrm{hr}^{-1}$ were simulated on the cover surface for the duration of an hour biweekly as a basis in this study. Eleven rainfall events were simulated in the period starting from November 2016 to April 2017. Fig. 2 (a) shows the summary of rainfall events which includes both natural and simulated rainfall. The soil loss, percentage of vegetated area, eroded soil profile and weather parameters were monitored during the entire experimental period. The eroded soil mass settled under rainwater was collected from all four chambers provided at the toe region of the sloped cover setup and the soil loss was evaluated based on the collected soil mass. $98 \%$ of the soil is recovered from the $2.5 \mathrm{~m}$ collection chamber present immediate to the pilot cover slope. The amount of soil erosion is expressed in terms of rate of soil loss $\left(\mathrm{kg} \cdot \mathrm{m}^{-2} \cdot \mathrm{s}^{-1}\right)$ by considering the total sloped surface area and the time of rainfall simulation.

The images of the nine sections were captured using an advanced photographic camera (NIKON D5200, Exposure time 1:4000 s, FL-26 mm, Aperture 4.2, ISO 1000) on weekly basis. The images were analysed using Matlab image processing tool to evaluate the percentage of vegetated area based on the colour index. Fig. 3 demonstrates the schematic process of calculating vegetation index using the image analysis. The average of readings from 9 sections was reported as the percentage vegetation for the given week. The depth of soil surface was also measured at 5 points on three horizontal axes (width-wise) in all these 


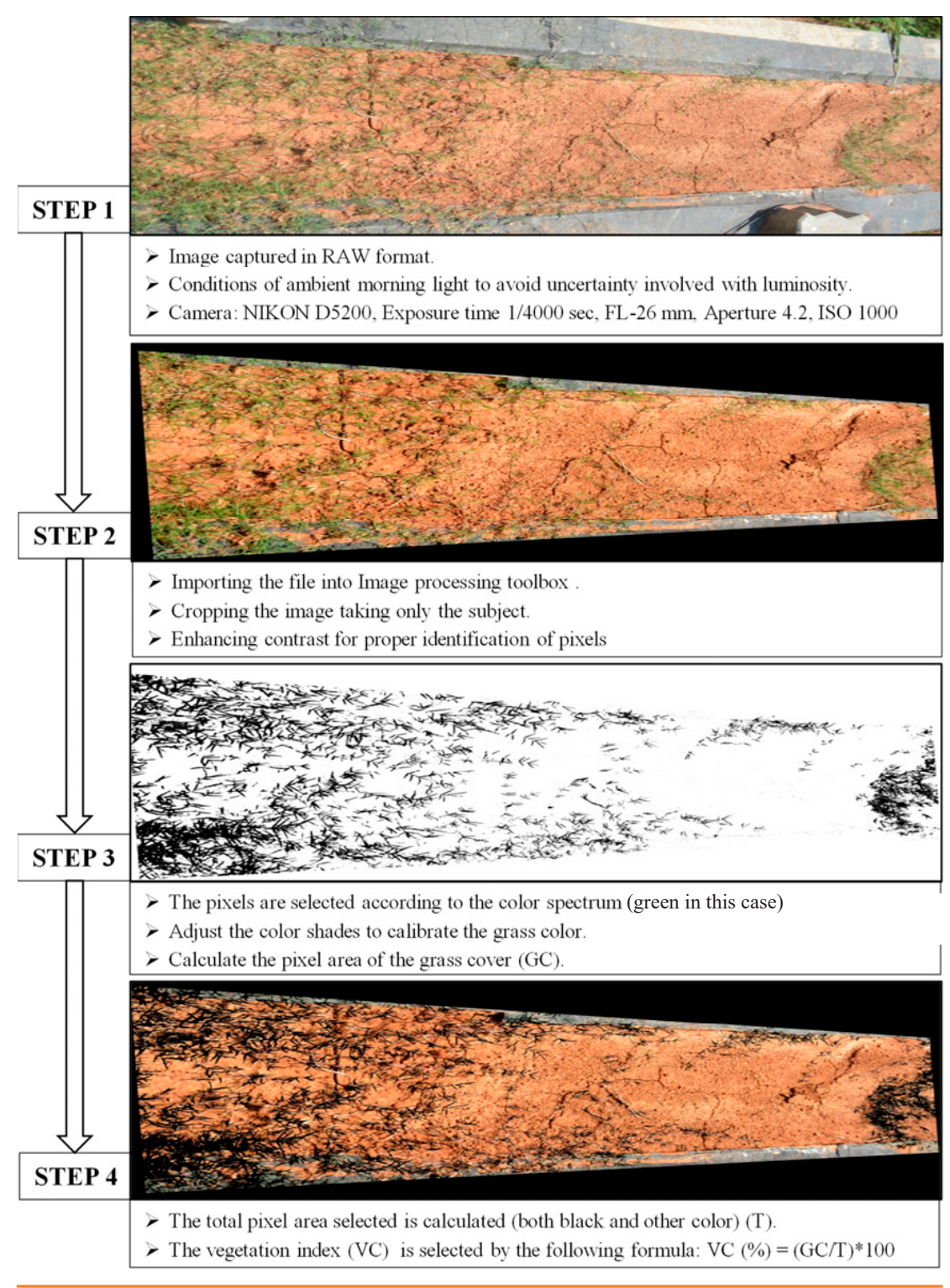

Figure 3 Schematic process of calculating vegetation index using image analysis

nine sections. A 3 dimensional spatial plot of observed data was reported to describe the changes in soil profile of the sloped surface.

\section{Results and discussion}

\section{Vegetation growth}

Fig. 4 (a) depicts the variation in green vegetation growth on the surface layer of field cover setup. The figure showed that the percentage of vegetated area consistently increased during the monitoring period except in the months of January and February of winter season. This may be due to the drop in its photosynthetic action in winter season (Jiang et al., 2017),

\section{Erosion rate}

Fig. 4 (b) details weekly variation of soil erosion from the surface layer of the experimental cover setup subjected to both natural and artificial rainfall. The Fig. 4 (b) clearly indicates that the erosion rate was mostly affected by the duration and intensity of rainfall events. Particularly, the soil erosion rate rose during the initial stage when the simulated rainfall of high intensity was applied. However, the effect of surface dryness was also noted during the summer season. For instance, the soil erosion in $16^{\text {th }}$ week was observed to be higher than in $17^{\text {th }}$ week, even though $16^{\text {th }}$ week received similar amount of rainfall as $17^{\text {th }}$ week. This indicates the probability of higher erosion when the soil surface was dry. The surface dryness can be ascertained from the temperature recordings depicted in Fig. 2 (b).

\section{Vegetation effect on soil erosion}

Fig. 4 (a) and (b) show that the soil erosion rate was found to be higher if the natural rainfall was higher during the initial days of field monitoring when the vegetation growth was absent on the surface layer. However, the erosion rate was seen to be comparatively higher during simulated artificial rainfall events. This may be due to its higher intensity and bigger size of artificial raindrops causing higher impacting force to erode the soil particles from the cover surface. The soil erosion rate induced by the artificial rainfall diminished over the time as the vegetation growth gradually covered larger area on the soil surface. The drop in vegetation growth and evapotranspiration rate in the month of January and February slightly affected the soil erosion induced by the artificial rainfall. The erosion rate was significantly reduced due to further growth of vegetation after these two months.

\section{Conclusion} attributed to higher temperature and rainfall (simulated events of $100 \mathrm{~mm}$ per 2 weeks) after first 24 weeks. Similar observations are reported by Propastin, Kappas, and Muratova (2008). However, the method of evaluating the vegetated area using image analysis has some limitations which were reported in the literature (Kondrlova et al. 2017). 


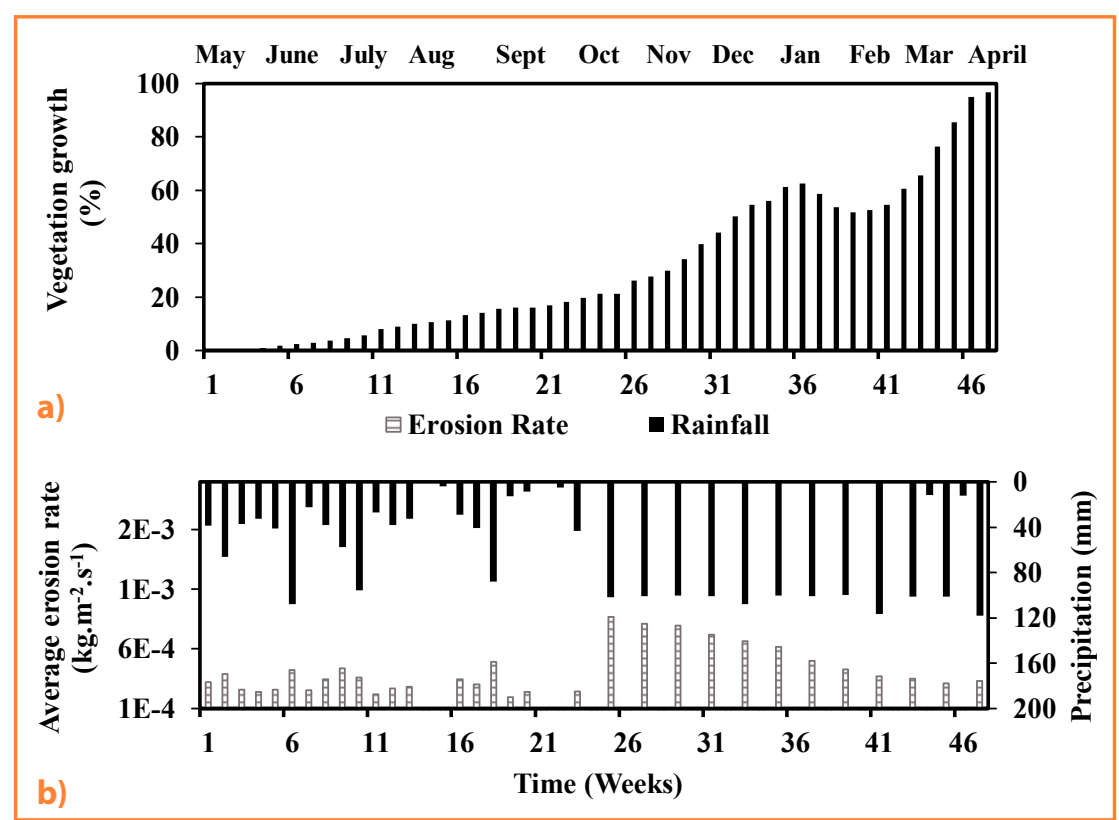

Figure 4 Temporal variation in (a) percentage of vegetated area and (b) average soil erosion rate on the cover surface layer subjected to natural and artificial rainfall events

growth due to lesser solar radiation causing inefficient photosynthetic activity during the winter season. The study also demonstrated that the cover surface encountered significant soil erosion due to heavy and prolonged rainfall events. Furthermore, the study indicates the considerable effects of the vegetation growth on the soil erosion from sloped cover surface. Soil erosion rate of any sloped earthen surface can be minimized by increasing the percentage of vegetated area.

\section{Acknowledgment}

Authors would like thankfully acknowledge board of research in nuclear sciences (BRNS), Department of Atomic Energy (DAE), India for the financial support provided for the work reported in this paper vide project no. 2013/36/06-BRNS.

\section{References}

ATUCHA, A. - MERWIN, I.A. - BROWN, M.G. GARDIAZABAL, F. - MENA, F. - ADRIAZOLA, C. 2013. Soil erosion, runoff and nutrient losses in an avocado (Persea americana Mill) hillside orchard under different groundcover management systems. In Plant and Soil, 2013, 368, pp. 393-406.

BUTT, M.J. - WAQAS, A. - MAHMOOD, R. 2010. The Combined Effect of Vegetation and Soil Erosion in the Water Resource Management. In Water Resources Management, 2010, 24, pp. 3701-3714.
CHRISTIANSEN, J.E. 1941. The uniformity of application of water by sprinkler systems. In Agricultural Engineering, vol. 22, 1941, no. 3, pp. 89-92.

DECAGON DEVICES Inc. 2015. Microclimate monitoring system for measuring various weather parameters, Operator's User Manual, Decagon Devices Inc., Pullman, WA, United States of America (USA).

EEA. 2013. Managing municipal solid waste - a review of achievements in 32 European counties. Publications Office of the European Union, Report No. 2, 2013, pp. 1-40.

HUVAJ-SARIHAN, N. - STARK, T.D. 2008. Back-Analyses of Landfill Slope Failures. In $6^{\text {th }}$ International Conference on Case Histories in Geotechnical Engineering. Arlington, VA. 2008, pp. 1-7.

JIANG, L. - JIAPAER, G. - BAO, A. - GUO, H. NDAYISABA, F. 2017. Science of the Total Environment Vegetation dynamics and responses to climate change and human activities in Central Asia. In Science of the Total Environment, 2017, 599-600, pp. 967-980.

KINCAID, D.C. 1996. Spray drop kinetic energy from irrigation sprinklers. In Transactions of the ASAE, vol. 39, 1996, no. 3, pp. 847-853.

KONDRLOVÁ, E. - HORÁK, J. - IGAZ, D. DOBIAŠOVÁ, D. 2017. The possibility of using digital images in assessment of plant canopy development and weed spread. In Acta Horticulturae et Regiotecturae, vol. 20, 2017, no. 2, pp. 35-39. T. - DEVOTTA, S. 2008. Hazardous waste management system in India: An overview.
KUMAR, S. - MUKHERJEE, S. - CHAKRABARTI,
In Critical Reviews in Environmental Science and Technology, vol. 38, 2008, no. 1, pp. 43-71.

LANDRETH, R.E. - DANIEL, D.E. - KOERNER, R.M. - SCHROEDER, P.R. - RICHARDSON, G.N. 1991. Design and construction of RCRA-CERCLA final covers. In Seminar Publication. Washington DC, 1991.

LUO, H. - ZHAO, T. - DONG, M. - GAO, J. PENG, X. - GUO, Y. - WANG, Z. - Liang, C. 2013. Field studies on the effects of three geotextiles on runoff and erosion of road slope in Beijing, China. In Catena, 2013, 109, pp. 150-156.

MORRIS, J.W.F. - BARLAZ, M.A. 2011. A performance-based system for the longterm management of municipal waste landfills. In Waste Management, vol. 31, 2011, no. 4, pp. 649-662.

NEARING, M.A. - YIN, S. - BORRELLI, P. POLYAKOV, V.O. 2017. Catena Rainfall erosivity: An historical review. In Catena, 2017, 157, pp. 357-362.

PROPASTIN, P.A. - KAPPAS, M. - MURATOVA, N.R. 2008. Inter-Annual Changes in Vegetation Activities and Their Relationship to Temperature and Precipitation in Central Asia from 1982 to 2003. vol. 12, 2008, no. 2, pp. 75-87.

PROSDOCIMI, M. - CERDÀ, A. - TAROLLI, P. 2016. Catena Soil water erosion on Mediterranean vineyards: A review. In Catena, 2016, 141, pp. 1-21.

SACHS, E. - SARAH, P. 2017. Catena Combined effect of rain temperature and antecedent soil moisture on runoff and erosion on Loess. In Catena, 2017, 158, pp. 213-218.

USEPA. 1989. Requirements for hazardous waste landfill design, construction, and closure. In Seminar publication. United States Environmental Protection Agency, Cincinnati, Report No. 625/4-89/022, 1989, pp. 1-127.

VEREECKEN, H. - KOLLET, S. - SIMMER, C. 2010. Patterns in Soil - Vegetation Atmosphere Systems: Monitoring, Modelling, and Data Assimilation. In Vadose Zone Journal, vol. 9, 2010, no. 4, pp. 821-827.

WANG, Q. - SONG, X. - LI, F. - HU, G. - LIU, Q. - ZHANG, E. - WANG, H. - DAVIES, R. 2015. Optimum ridge - furrow ratio and suitable ridge-mulching material for Alfalfa production in rainwater harvesting in semi-arid regions of China. In Field Crops Research, 2015, 180, pp. 186-196.

YAMSANI, S.K. - SREEDEEP, S. - RAKESH, R.R. 2016. Frictional and Interface Frictional Characteristics of Multi-Layer Cover System Materials and Its Impact on Overall Stability. In International Journal of Geosynthetics and Ground Engineering, vol. 2, 2016, no. 3, pp. 1-9. 